\title{
A meta-analysis and systematic review of holmium laser treatment of bladder stones
}

\author{
Jie $\mathrm{Lv}^{1}$, Ning Wang ${ }^{1}$, Yongsheng Zhu' ${ }^{2}$, Qian $\mathrm{Luo}^{1}$, Yongxian $\mathrm{Li}^{1}$, Jian $\mathrm{Li}^{1}$ \\ ${ }^{1}$ Department of Urology, Luzhou People's Hospital, Luzhou, China; ${ }^{2}$ Department of Urology, Affiliated Chinese Medicine Hospital of Southwest \\ Medical University, Luzhou, China \\ Contributions: (I) Conception and design: J Lv, N Wang, J Li; (II) Administrative support: Q Luo; (III) Provision of study materials or patients: J Lv, \\ N Wang, Y Zhu, Y Li, J Li; (IV) Collection and assembly of data: All authors; (V) Data analysis and interpretation: J Lv, Y Zhu, Q Luo, Y Li, J Li; (VI) \\ Manuscript writing: All authors; (VII) Final approval of manuscript: All authors. \\ Correspondence to: Jian Li. Section 316, Jiu Gu Da Dao, Jiangyang District, Luzhou, China. Email: ywblj666666@163.com.
}

\begin{abstract}
Background: Holmium lasers have been used to treat bladder stones and achieve good therapeutic effects, but its efficacy remains to be explored.

Methods: The PubMed, Embase, Medline, Ovid, Springer, and Web of Sciences databases were searched from their establishment to December 31, 2020. Studies of randomized control trials (RCTs) examining the treatment of vesical calculi by holmium laser lithotripsy were identified. The Cochrane Handbook for Systematic Reviews of Intervention 5.0.2 was used to assess risk bias, and Rev Man5.3 was used to conduct the meta-analysis.

Results: A total of 10 studies, comprising 1,642 subjects, were included. The meta-analysis results showed that the surgery time and the hospitalization time of patients treated with holmium laser lithotripsy decreased, and the calculus removal rate increased. The experimental group had a lower incidence of adverse reactions, such as postoperative urinary tract infection, mucosal damage, vesical perforation, residual calculi, hematuria, and abdominal pain than the control group; however, no notable difference was observed in relation to surgery time, hospital stay, the calculus removal rate, mucosal damage, bladder perforation, hematuria, and abdominal pain between the 2 groups.

Discussion: Holmium laser lithotripsy significantly reduced the hospitalization time of patients treated with holmium laser lithotripsy and elevated the removal rate.
\end{abstract}

Keywords: Holmium laser lithotripsy; pneumatic lithotripsy; urological diseases; vesical calculi; clinical efficacy

Submitted Jun 09, 2021. Accepted for publication Jul 27, 2021.

doi: $10.21037 /$ tau-21-563

View this article at: https://dx.doi.org/10.21037/tau-21-563

\section{Introduction}

Vesical calculi form in the bladder. In relation to the pathogenesis of vesical calculi, with the exception of cases of malnutrition, the disease is secondary to lower urinary tract obstruction, infection, foreign bodies in the bladder, and metabolic diseases (1). Clinically, it mainly manifests as pain and hematuria, and its severity depends on the location, size, and the presence or absence of complications (2).

The principle of clinical treatment is to remove the calculi and prevent them from recurring. Small calculi can be expelled spontaneously through the urethra; however, larger stones that cannot be expelled spontaneously should be treated with surgery (3). Surgical lithotripsy is the traditional suprapubic cystotomy and lithotripsy; however, due to the extensive damage it causes, it is not conducive to patient recovery (4). Extracorporeal lithotripsy is a new method that mainly includes extracorporeal shock wave lithotripsy, hydroelectric shock lithotripsy, ultrasonic lithotripsy, and lithotripter lithotripsy. Holmium laser lithotripsy is a new type of treatment for urinary calculi (5). With yttrium aluminum garnet as the activation medium, 
the pulsed solid laser device, doped with sensitized ion chromium, energy transfer ion thulium, and activated ion holmium, produces a new type of laser that can vaporize the water between the end of the fiber and the calculus. The energy is then transferred to the calculus to crush it into powder. The water absorbs a great deal of energy, reducing damage to surrounding tissue. Additionally, the holmium laser only penetrates the body tissue by $0.4 \mathrm{~mm}$, and thus has a high level of safety (6). However, to date, very little research appears to have been conducted on the efficacy of holmium laser lithotripsy on vesical calculi. To confirm the efficacy of this technology, relevant randomized control trials (RCTs) were retrieved, and a meta-analysis was conducted to undertake a systematic analysis. We present the following article in accordance with the PRISMA reporting checklist (available at https://dx.doi.org/10.21037/ tau-21-563).

\section{Methods}

\section{Literature inclusion and exclusion criteria}

Inclusion criteria: (I) the research subjects were patients who had been clinically diagnosed with vesical calculi; (II) the articles were RCTs in the English language; and (III) patients in the experimental group underwent holmium laser lithotripsy, and those in the control group underwent pneumatic lithotripsy (the baseline data of the 2 groups had to be comparable; (IV) the patients could be treated by conservative treatment; and (V) the evaluation indicators included patients' satisfaction after surgery and the occurrence of adverse reactions.

Exclusion criteria: (I) a RCT had not been conducted; rather, the article was about a retrospective study, case report, or cohort study; (II) the research subjects were animals; (III) the article was unpublished, such as a degree thesis, or was in a language other than English; (IV) patients in the experimental group had undergone a cystectomy, or another conservative treatment; $(\mathrm{V})$ the patients had other diseases; and/or (VI) the research data was incomplete.

\section{Literature retrieve}

The PubMed, Embase, Medline, Ovid, Springer, and Web of Sciences databases were searched since their establishment to December 31, 2020, with "Holmium laser lithotripsy," "Pneumatic lithotripsy," "Urology Surgery," and "Vesical Calculi," used as search terms.

\section{Literature screening}

After the articles were retrieved, NoreExpress 3.2 was used to identify duplicates, which were then removed. Next, the 2 researchers read the titles and abstracts to eliminate articles that obviously did not meet the inclusion criteria.

\section{Data extraction}

The following data were collated: (I) the title and the name of the first author (only 1), the publication time, and the research content; (II) the age of the patients, the sample size, and baseline comparability; (III) the research plan, intervention methods, and the anti-bias measures; and (IV) the outcome indexes and data.

\section{Bias risk assessment}

The bias risk was evaluated concerning the generation of the random sequence, the blind method applied to patients and the experimental personnel, the blind method applied to outcomes evaluation, whether the data was complete, whether there was a selective report, and whether there were other bias sources.

\section{Statistical analysis}

The risk of bias was assessed using the Cochrane Handbook for Systematic Reviews of Interventions 5.0.2. STATA11.0 software was used to count the included literature. RevMan5.3 was used to perform the meta-analysis. Relative risk (RR) was used as the effect size for the binary variables in the count data, and the $95 \%$ confidence interval (CI) was calculated. The $\mathrm{I}^{2}$ test was used to evaluate the heterogeneity of the included literature. If $\mathrm{I}^{2}$ was $>50 \%$, a random-effects model (REM) was used; if $\mathrm{I}^{2}$ was $<50 \%$, a fixed-effects model (FEM) was used. The combined effect size test adopted a U-test and $95 \%$ CI. The U-test result was expressed as a $\mathrm{P}$ value; a $\mathrm{P}<0.05$ was the threshold for significance.

\section{Results}

\section{Literature retrieve results}

Initially, a total of 432 references were identified, among which 112 studies were from PubMed, 58 were from Embase, 42 were from Medline, 51 were from Springer, 28 were from Ovid, and 141 were from Web of Sciences. 


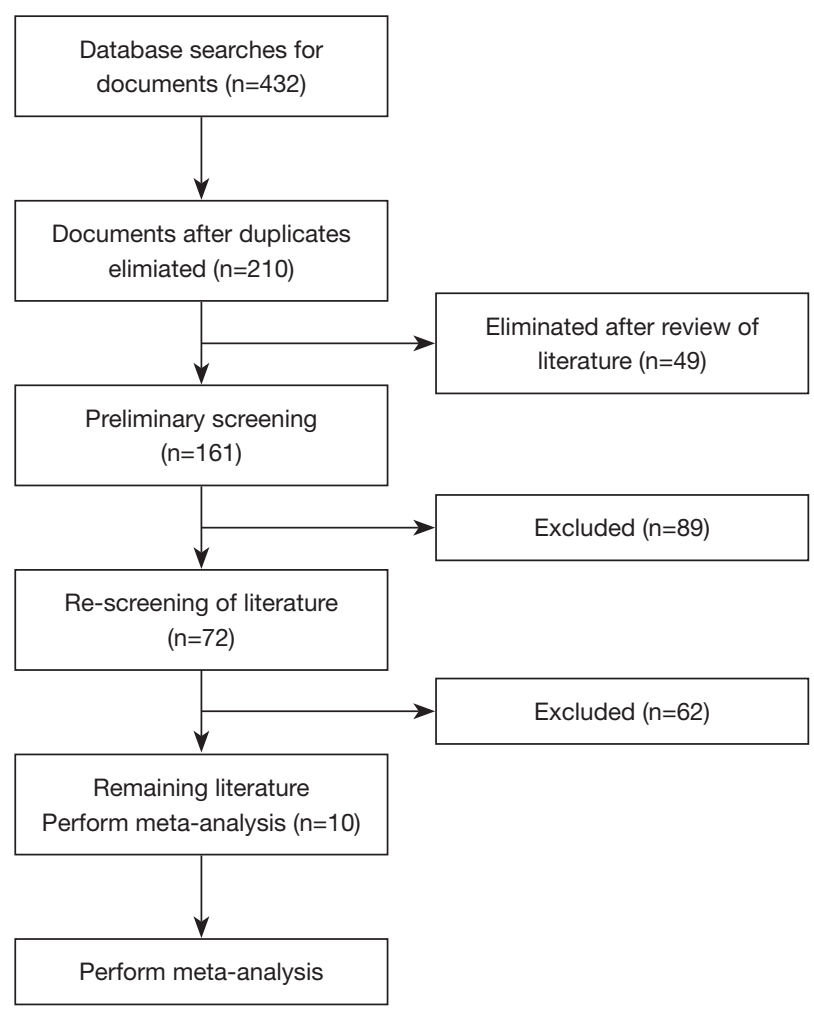

Figure 1 A flow chart depicting the literature retrieve process.

Next, NoteExpress3.2 was used to exclude 222 duplicates. Subsequently, the 2 experts read the title and the abstract of each article to exclude those that obviously did not meet the inclusion criteria. After this step, 72 studies were left. After the 2 experts read the full text of each of the 72 articles, 10 studies remained, which were included in the meta-analysis. All articles described RCTs that had been published between 2000-2020. In total, the 12 studies comprised 1,642 research subjects (3-14) (see Figure 1 and Table 1).

\section{The bias risk assessment}

The assessment items included: (I) the generation of the random sequence: 10 of the included studies stated that the subjects were grouped based on different surgery methods, which indicated a low risk; (II) allocation concealment: none of the 10 studies mentioned whether allocation concealment was adopted, which indicated an unclear risk; (III) the blind method for the subjects: 7 of the 10 studies mentioned that the subjects signed informed consent forms, but it was unclear whether the blind method had been applied to the subjects, which indicated an unclear risk; (IV) the blind method for the assessors: none of the 10 references mentioned whether the blind method had been applied to the assessors, which indicated an unclear risk; (V) the complete data: all of the 10 studies had complete results data, which indicated a low risk; (VI) selective reporting: all of the 10 studies were free of selective reporting, which indicated a low risk; and (VII) other bias risks: 6 of the 10 studies had inconsistent populations between groups, which indicated a high risk, and it was not clear whether there were other bias risks in the remaining 4 studies, which indicated an unclear risk. Figures 2 and 3 showed the bias risk assessment results.

\section{Surgery time}

In this study, 7 studies analyzed surgery time. The heterogeneity test results $\left(\mathrm{I}^{2}=99 \%, \mathrm{P}<0.00001\right)$ indicated a certain degree of heterogeneity; thus, the REM was used. The combined effect size was $\mathrm{MD}=-5.59 ; 95 \% \mathrm{CI},-15.26$ to $4.09 ; Z=1.13 ; P=0.26$, which suggested that the surgery time of holmium laser lithotripsy was shorter versus control group (Figure 4).

\section{Length of hospital stay}

There were 3 studies analyzing the length of hospital stay. The heterogeneity test results $\left(\mathrm{I}^{2}=0 \%, \mathrm{P}=0.42\right)$ indicated no heterogeneity; thus, the FEM was used. The combined effect size was $M D=-0.26 ; 95 \% C I,-0.54$ to $0.02 ; Z=1.85$; $\mathrm{P}=0.06$, which suggested that the hospital stay of patients treated by holmium laser lithotripsy was shorter versus the control group (Figure 5).

\section{The removal rate}

Four studies in the meta-analysis analyzed the calculus removal rate. The heterogeneity test results $\left(\mathrm{I}^{2}=58 \%\right.$, $\mathrm{P}=0.07)$ indicated a certain degree of heterogeneity; thus, the REM was used. The combined effect size was $\mathrm{MD}=4.36 ; 95 \% \mathrm{CI}, 0.95-20.07 ; \mathrm{Z}=1.89 ; \mathrm{P}=0.06$, which suggested that the experimental group had a higher calculus removal rate (Figure 6).

\section{Urinary tract infection}

In this study, 5 studies analyzed postoperative urinary tract infection. The heterogeneity test results $\left(\mathrm{I}^{2}=13 \%, \mathrm{P}=0.33\right)$ 
Table 1 Characteristics of the articles included in the meta-analysis

\begin{tabular}{|c|c|c|c|c|}
\hline The first author & Published year & Group & Sample size & Counter measure \\
\hline Ercil & & Control & 29 & Pneumatic lithotripsy \\
\hline \multirow[t]{2}{*}{ Gangkak } & 2016 & Experimental & 12 & Holmium laser lithotripsy \\
\hline & & Control & 13 & Pneumatic lithotripsy \\
\hline $\mathrm{Li}$ & & Control & 489 & Pneumatic lithotripsy \\
\hline \multirow[t]{2}{*}{ Cimino } & 2014 & Experimental & 60 & Holmium laser lithotripsy \\
\hline & & Control & 57 & Pneumatic lithotripsy \\
\hline Razzaghi & 2013 & Experimental & 56 & Holmium laser lithotripsy \\
\hline Kassem & & Control & 40 & Pneumatic lithotripsy \\
\hline \multirow[t]{2}{*}{ Binbay } & 2011 & Experimental & 40 & Holmium laser lithotripsy \\
\hline & & Control & 40 & Pneumatic lithotripsy \\
\hline \multirow[t]{2}{*}{ Garg } & 2009 & Experimental & 30 & Holmium laser lithotripsy \\
\hline & & Control & 25 & Pneumatic lithotripsy \\
\hline \multirow[t]{2}{*}{ Maghsoudi } & 2008 & Experimental & 39 & Holmium laser lithotripsy \\
\hline & & Control & 40 & Pneumatic lithotripsy \\
\hline Manohar & 2008 & Experimental & 25 & Holmium laser lithotripsy \\
\hline
\end{tabular}

Random sequence generation (selection bias)

Allocation concealment (selection bias)

Blinding of participants and personnel (performance bias)

Blinding of outcome assessment (detection bias)

Incomplete outcome data (attrition bias)

Selective reporting (reporting bias)

Other bias

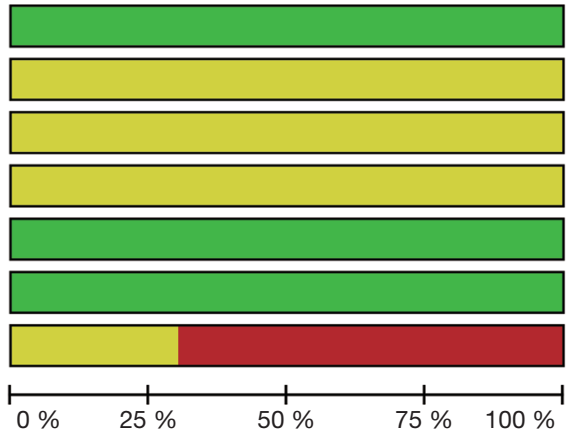

Low risk of bias

Unclear risk of bias

High risk of bias

Figure 2 Bar chart showing the bias risk assessment results of the included studies. 


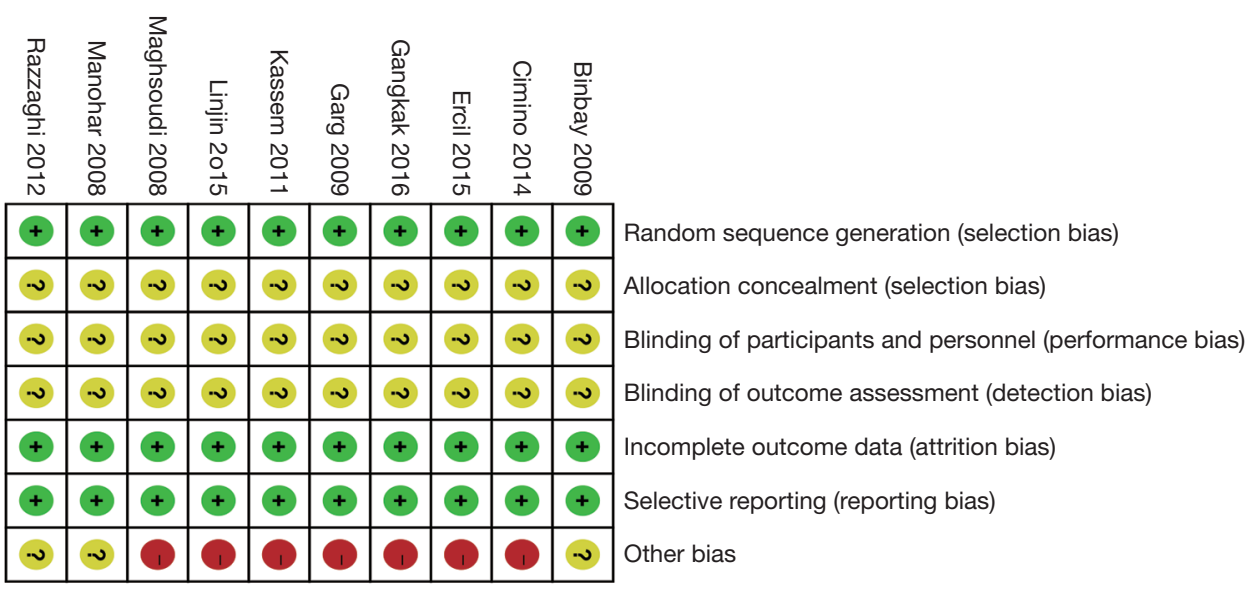

Figure 3 Diagram showing the bias risk assessment results of the included studies.

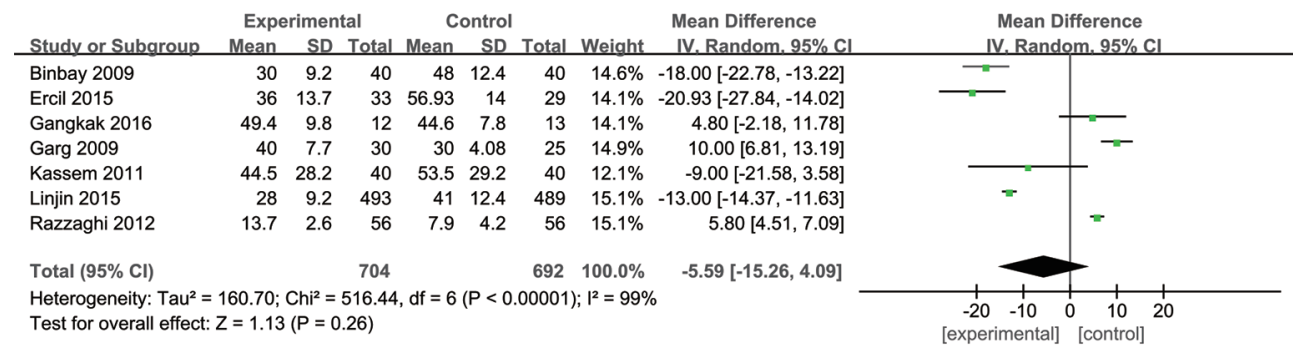

Figure 4 Forest plot showing surgery time.

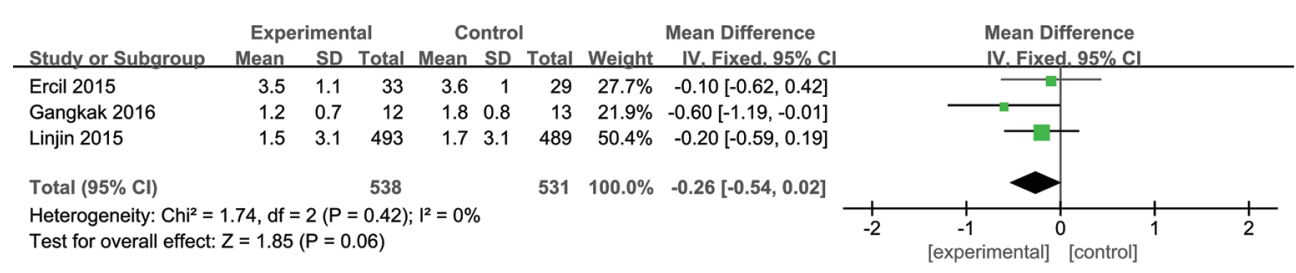

Figure 5 Forest plot showing the hospital stay.

indicated no heterogeneity; thus, the FEM was used. The combined effect size was $M D=0.69 ; 95 \%$ CI, 0.49-0.98; $\mathrm{Z}=2.05 ; \mathrm{P}=0.04$, which suggested that the incidence of urinary tract infection in the experimental group was lower (Figure 7).

\section{Mucosal damage}

In this study, 5 studies analyzed patients' postoperative mucosal damage. The heterogeneity test results $\left(\mathrm{I}^{2}=0 \%\right.$, $\mathrm{P}=0.5$ ) indicated no heterogeneity; thus, the FEM was used.
The combined effect size was $\mathrm{MD}=0.67$; $95 \%$ CI, $0.31-$ $1.41 ; Z=1.06 ; P=0.29$, which suggested that the mucosal damage of patients in experimental group was less severe (Figure 8).

\section{Vesical perforation}

In this study, 6 studies analyzed the postoperative vesical perforation of patients. The heterogeneity test results $\left(\mathrm{I}^{2}=0 \%\right.$, $\mathrm{P}=0.74$ ) indicated no heterogeneity; thus, the FEM was used. The combined effect size was $\mathrm{MD}=0.9 ; 95 \% \mathrm{CI}, 0.49-1.65$; 


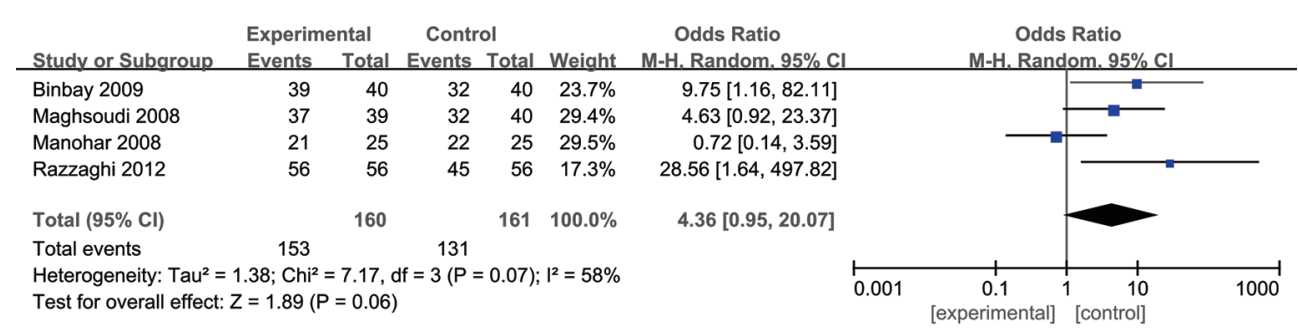

Figure 6 Forest chart showing the calculus removal rate.

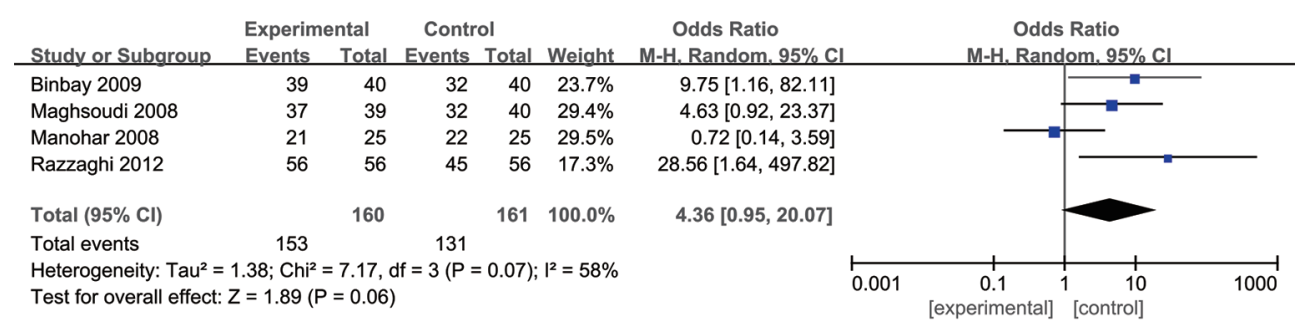

Figure 7 Forest plot showing the incidence of urinary tract infection.

\begin{tabular}{|c|c|c|c|c|c|}
\hline \multirow[b]{2}{*}{ Study or Subgroup } & \multicolumn{2}{|c|}{ Experimental } & \multicolumn{2}{|c|}{ Control } & \multirow[b]{2}{*}{ Weight } \\
\hline & Events & Total & Events & Total & \\
\hline Cimino 2014 & 2 & 60 & 0 & 57 & $2.9 \%$ \\
\hline Ercil 2015 & 3 & 33 & 5 & 29 & $28.8 \%$ \\
\hline Linjin 2015 & 1 & 493 & 5 & 489 & $29.8 \%$ \\
\hline Manohar 2008 & 2 & 25 & 3 & 25 & $16.4 \%$ \\
\hline Razzaghi 2012 & 4 & 56 & 4 & 56 & $22.1 \%$ \\
\hline Total $(95 \% \mathrm{Cl})$ & & 667 & & 656 & $100.0 \%$ \\
\hline Total events & 12 & & 17 & & \\
\hline Heterogeneity: $\mathrm{Chi}^{2}=$ & $36, d f=4$ & $P=0$. & $0) ; 1^{2}=0^{\circ}$ & & \\
\hline Test for overall effec & $=1.06$ & $0.29)$ & & & \\
\hline
\end{tabular}

Figure 8 Forest chart showing the mucosal damage.

$\mathrm{Z}=0.34 ; \mathrm{P}=0.74$, which suggested that the vesical perforation in the experimental group was less severe (Figure 9).

\section{Residual calculi}

In this study, 6 studies analyzed the postoperative residual calculi rate. The heterogeneity test results $\left(\mathrm{I}^{2}=0 \%\right.$, $\mathrm{P}=0.84$ ) indicated no heterogeneity; thus, the FEM was used. The combined effect size was MD $=0.32 ; 95 \% \mathrm{CI}$, $0.18-0.58 ; \mathrm{Z}=3.8 ; \mathrm{P}=0.0001$, which suggested that the residual calculi rate in the experimental group was lower (Figure 10).

\section{Hematuria}

In this study, 3 studies analyzed the postoperative hematuria of patients. The heterogeneity test results $\left(\mathrm{I}^{2}=0 \%\right.$, $\mathrm{P}=0.13$ ) indicated no heterogeneity; thus, the FEM was used. The combined effect size was MD $=0.62 ; 95 \% \mathrm{CI}$, $0.33-1.15 ; Z=1.53 ; \mathrm{P}=0.13$, which suggested that the incidence of hematuria was lower in the experimental group (Figure 11).

\section{Abdominal pain}

In this study, 3 studies analyzed the postoperative abdominal pain of patients. The heterogeneity test results $\left(\mathrm{I}^{2}=0 \%\right.$, $\mathrm{P}=0.68$ ) indicated no heterogeneity; thus, the FEM was used for the analysis. The combined effect size was $(M D=0.78$; 95\% CI, 0.6-1.02; $\mathrm{Z}=1.84 ; \mathrm{P}=0.07$ ), which suggested that the incidence of hematuria was lower in the experimental group (Figure 12). 


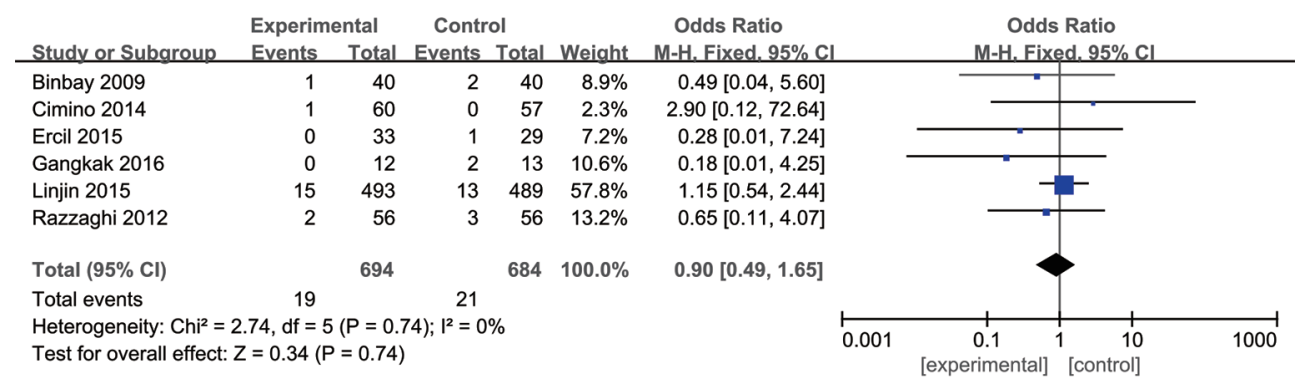

Figure 9 Forest plot showing vesical perforation.

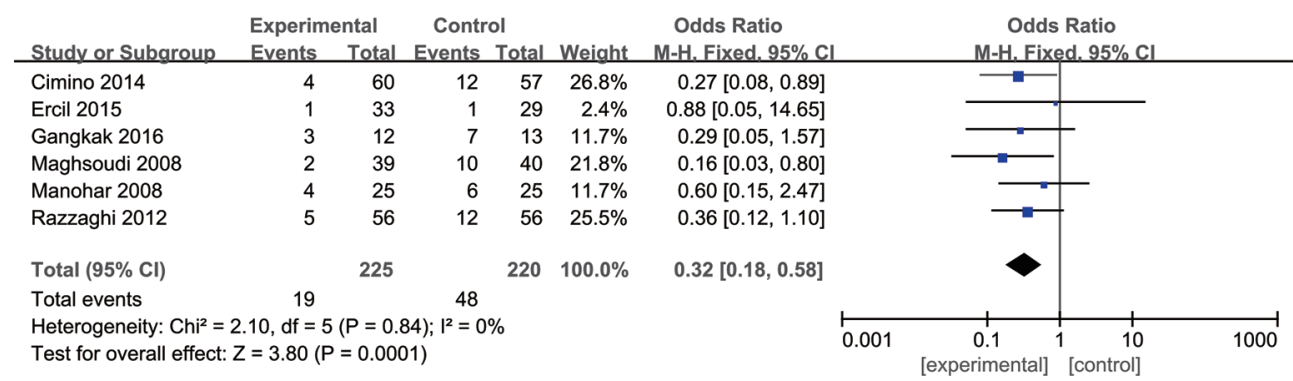

Figure 10 Forest plot showing the residual calculi rate.

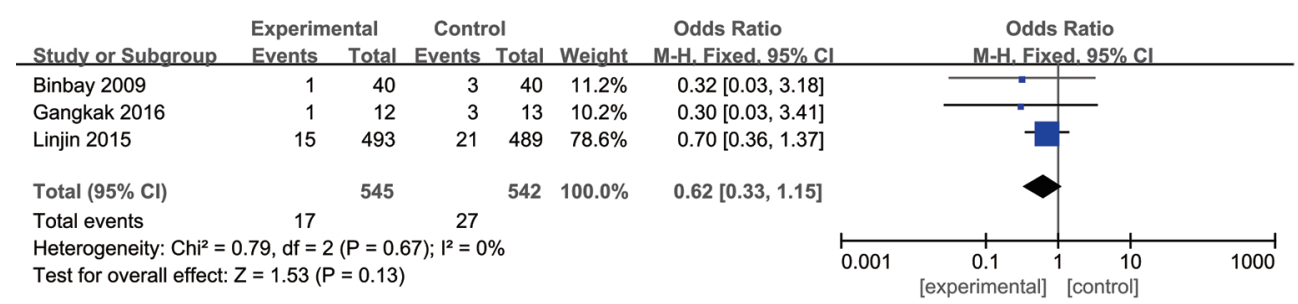

Figure 11 Forest plot showing hematuria.

\begin{tabular}{|c|c|c|c|c|c|c|c|c|c|c|}
\hline Studv or Subgroup & \multicolumn{2}{|c|}{ Experimental } & \multicolumn{2}{|c|}{ Control } & Weight & $\begin{array}{l}\text { Odds Ratio } \\
\text { M-H. Fixed. } 95 \% \mathrm{Cl}\end{array}$ & \multicolumn{4}{|c|}{$\begin{array}{c}\text { Odds Ratio } \\
\text { M-H. Fixed. } 95 \% \mathrm{Cl}\end{array}$} \\
\hline Cimino 2014 & 2 & 60 & 4 & 57 & $3.2 \%$ & $0.46[0.08,2.60]$ & & & & \\
\hline Kassem 2011 & 4 & 40 & 7 & 40 & $5.0 \%$ & $0.52[0.14,1.95]$ & & & & \\
\hline Linjin 2015 & 137 & 493 & 158 & 489 & $91.8 \%$ & $0.81[0.61,1.06]$ & & & & \\
\hline Total $(95 \% \mathrm{Cl})$ & & 593 & & 586 & $100.0 \%$ & $0.78[0.60,1.02]$ & & & & \\
\hline Total events & 143 & & 169 & & & & & & & \\
\hline $\begin{array}{l}\text { Heterogeneity: } \mathrm{Chi}^{2}= \\
\text { Test for overall effect }\end{array}$ & $\begin{array}{l}.77, d f=2 \\
=1.84(P\end{array}$ & $\begin{array}{l}(P=0.6 \\
=0.07)\end{array}$ & 8); $1^{2}=0$ & & & & 0.01 & $\begin{array}{c}0.1 \\
\text { [experimental] }\end{array}$ & $1_{\text {[control] }} 1$ & 100 \\
\hline
\end{tabular}

Figure 12 Forest plot showing postoperative abdominal pain.

\section{Publication bias}

As shown in Figure 13, hospital stay, calculus removal rate, postoperative urinary tract infection, mucosal damage, bladder perforation, residual calculi rate, hematuria, and abdominal pain were basically distributed within the CI, and article bias was low; however, the scattered points of surgery time were outside the CI, suggesting that the included articles had a certain publication bias. 

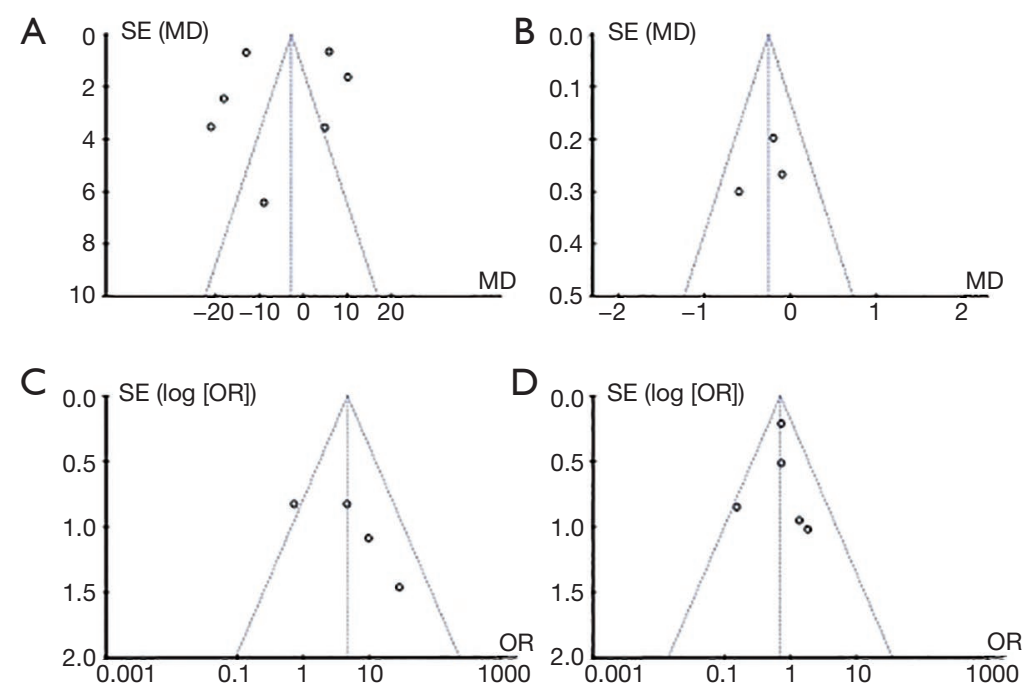

E

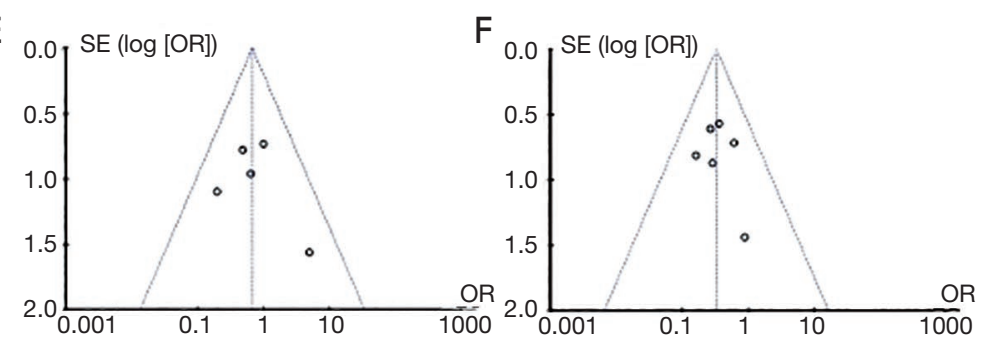

G

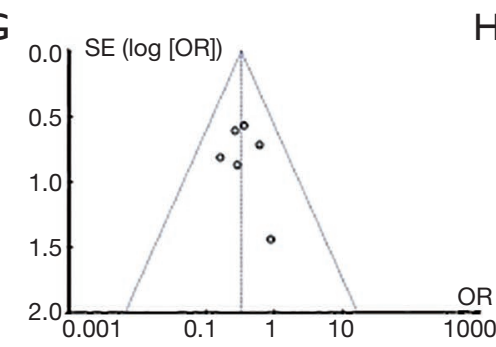

$\mathrm{H}_{0.0} \mathrm{SE}(\log [\mathrm{OR}])$

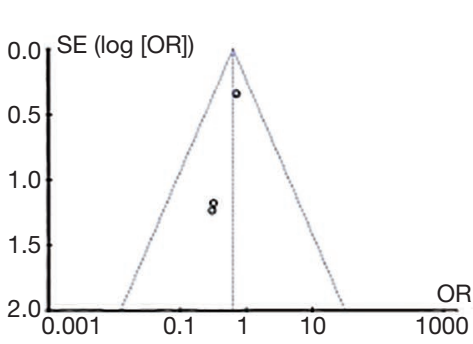

I

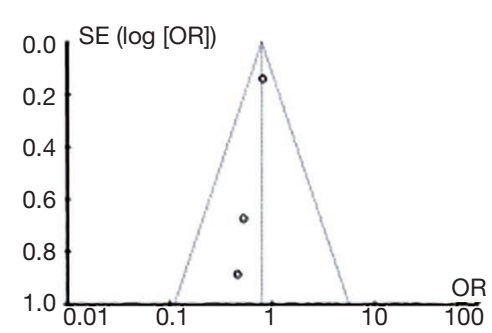

Figure 13 Funnel chart showing various indexes. (A) Surgery time; (B) hospital stay; (C) calculus removal rate; (D) urinary tract infection; (E) mucosal damage; (F) bladder perforation; $(\mathrm{G})$ residual calculi rate; $(\mathrm{H})$ hematuria; (I) abdominal pain.

\section{Discussion}

Vesical calculi can be divided into primary and secondary vesical calculi (15). The former refers to stones formed in the bladder that mostly arise due to malnutrition and occur more frequently in children (16). The latter refers to stones from upper urinary tract or secondary to lower urinary tract obstruction, infection, bladder foreign body, or neurogenic 
bladder . In developed countries, vesical calculi mainly occur in elderly men who often suffer from prostatic hyperplasia or urethral stricture (17). Conversely, in developing countries, the disease is more common in children and less common in women than men. If not treated in time, it will cause urinary tract infection and obstruction, resulting in poor drainage, and even leading to kidney failure in severe cases. Errors can occur in traditional lithotripsy treatments, and there are always residual stones that can cause a secondary blockage. Further, as the recovery effects are poor, it has limited clinical use (18). Developments in medical technology led to the introduction of the holmium laser lithotripsy treatment method, which has significantly improved the therapeutic effects and safety of patients, and reduced patients' adverse reactions after the surgery (19-21).

A total of 10 studies were included. It was found that the experimental group had shorter the surgery time and hospital stay, and a higher calculus removal rate. Studies have shown that, holmium laser lithotripsy demonstrates good safety and has been extensively used (22).

Extracorporeal shock wave lithotripsy uses hydroelectric or electromagnetic shock wave generators to emit highenergy shock waves that penetrate the human body, and crush the stones. The stone fragments are naturally discharged. However, the shock waves also cause tissue damage, such as the destruction of glomeruli and tubules, and ureteral stenosis (23). Similarly, when pneumatic lithotripsy is used to treat middle and lower ureteral calculi, it is easy to flush stones back into the upper ureter or kidney, and as the method can only be used under rigid ureteroscopy, it cannot be used to treat upper ureteral calculi and kidney stones (24). Compared with the 2 methods mentioned above, holmium laser lithotripsy demonstrates better therapeutic effects. As the stones rarely move during the lithotripsy process and the backlash rate is very low, its efficiency is high (25). The cystoscopy, ureteroscopy, and percutaneous nephroscope can directly crush the stones without causing tissue damage. Additionally, the holmium laser fiber is flexible and can not only be inserted through a rigid ureteroscope, but also through a flexible ureteroscope for lithotripsy (26). Thus, it can effectively crush stones in any part of the body.

\section{Conclusions}

In this meta-analysis, a total of 10 references were included, comprising 1,642 patients with vesical calculi. The investigation confirmed that compared to pneumatic lithotripsy, holmium laser lithotripsy significantly reduces the incidence of postoperative adverse reactions, shortens surgery time, and lowers the calculus removal rate of patients, and thus demonstrates superior capabilities in treating vesical calculi. However, this study had some limitations that should be noted. First, some articles exhibited large publication biases. Second, the sample size was small, which may have reduced the power of the meta-analysis results. In the future, a high-quality study with an expanded sample size needs to be conducted to further verify the efficacy of holmium laser lithotripsy in the treatment of vesical calculi.

\section{Acknowledgments}

Funding: None.

\section{Footnote}

Reporting Checklist: The authors have completed the PRISMA reporting checklist. Available at https://dx.doi. org/10.21037/tau-21-563

Conflicts of Interest: All authors have completed the ICMJE uniform disclosure form (available at https://dx.doi. org/10.21037/tau-21-563). The authors have no conflicts of interest to declare.

Ethical Statement: The authors are accountable for all aspects of the work in ensuring that questions related to the accuracy or integrity of any part of the work are appropriately investigated and resolved.

Open Access Statement: This is an Open Access article distributed in accordance with the Creative Commons Attribution-NonCommercial-NoDerivs 4.0 International License (CC BY-NC-ND 4.0), which permits the noncommercial replication and distribution of the article with the strict proviso that no changes or edits are made and the original work is properly cited (including links to both the formal publication through the relevant DOI and the license). See: https://creativecommons.org/licenses/by-nc-nd/4.0/.

\section{References}

1. Li J, Yu H, Zhou P, et al. Application of flexible ureteroscopy combined with holmium laser lithotripsy and their therapeutic efficacy in the treatment of upper urinary stones in children and infants. Urol J 2019;16:343-6. 
2. Garg M, Kumar M, Goel A, et al. Application of the holmium laser lithotripsy for bladder stones under local anaesthesia: a prospective analysis. Urologia 2015;82:219-22.

3. Gangkak G, Yadav SS, Tomar V, et al. Pneumatic cystolithotripsy versus holmium:yag laser cystolithotripsy in the treatment of pediatric bladder stones: a prospective randomized study. Pediatr Surg Int 2016;32:609-14.

4. Ercil H, Altunkol A, Alma E, et al. Comparison of Ho:Yag laser and pneumatic lithotripsy combined with transurethral prostatectomy in high burden bladder stones with benign prostatic hyperplasia. Asian J Surg 2016;39:238-42.

5. Sharma A, Garg G, Sharma A, et al. Comparison of electrocautery versus holmium laser energy source for transurethral ureterocele incision: an outcome analysis from a tertiary care institute. Lasers Med Sci 2021;36:521-8.

6. Romero-Otero J, García González L, García-Gómez B, et al. Analysis of Holmium Laser Enucleation of the Prostate in a High-Volume Center: The Impact of Concomitant Holmium Laser Cystolitholapaxy. J Endourol 2019;33:564-9.

7. Li L, Pan Y, Weng Z, et al. A Prospective Randomized Trial Comparing Pneumatic Lithotripsy and Holmium Laser for Management of Middle and Distal Ureteral Calculi. J Endourol 2015;29:883-7.

8. Cimino S, Favilla V, Russo GI, et al. Pneumatic lithotripsy versus holmium:YAG laser lithotripsy for the treatment of single ureteral stones: a prospective, single-blinded study. Urol Int 2014;92:468-72.

9. Razzaghi MR, Razi A, Mazloomfard MM, et al. Safety and efficacy of pneumatic lithotripters versus holmium laser in management of ureteral calculi: a randomized clinical trial. Urol J 2013;10:762-6.

10. Kassem A, Elfayoumy H, Elsaied W, et al. Laser and pneumatic lithotripsy in the endoscopic management of large ureteric stones: a comparative study. Urol Int 2012;88:311-5.

11. Binbay M, Tepeler A, Singh A, et al. Evaluation of pneumatic versus holmium:YAG laser lithotripsy for impacted ureteral stones. Int Urol Nephrol 2011;43:989-95.

12. Garg S, Mandal AK, Singh SK, et al. Ureteroscopic laser lithotripsy versus ballistic lithotripsy for treatment of ureteric stones: a prospective comparative study. Urol Int 2009;82:341-5.

13. Maghsoudi R, Amjadi M, Norizadeh D, et al. Treatment of ureteral stones: A prospective randomized controlled trial on comparison of Ho:YAG laser and pneumatic lithotripsy. Indian J Urol 2008;24:352-4.

14. Manohar T, Ganpule A, Desai M. Comparative evaluation of Swiss LithoClast 2 and holmium:YAG laser lithotripsy for impacted upper-ureteral stones. J Endourol 2008;22:443-6.

15. Zhang X, Yu J, Yang R. Minimally invasive management with holmium laser in total urinary tract calculi. Photomed Laser Surg 2013;31:230-5.

16. Goyal NK, Goel A, Sankhwar S. Transurethral holmiumYAG laser lithotripsy for large symptomatic prostatic calculi: initial experience. Urolithiasis 2013;41:355-9.

17. Shah HN, Hegde SS, Shah JN, et al. Simultaneous transurethral cystolithotripsy with holmium laser enucleation of the prostate: a prospective feasibility study and review of literature. BJU Int 2007;99:595-600.

18. Kawahara T, Ito $\mathrm{H}$, Terao $\mathrm{H}$, et al. Stone area and volume are correlated with operative time for cystolithotripsy for bladder calculi using a holmium: yttrium garnet laser. Scand J Urol Nephrol 2012;46:298-303.

19. May KA, Pleasant RS, Howard RD, et al. Failure of holmium:yttrium-aluminum-garnet laser lithotripsy in two horses with calculi in the urinary bladder. J Am Vet Med Assoc 2001;219:957-61, 939.

20. Yang B, Ning H, Liu Z, et al. Safety and Efficacy of Flexible Ureteroscopy in Combination with Holmium Laser Lithotripsy for the Treatment of Bilateral Upper Urinary Tract Calculi. Urol Int 2017;98:418-24.

21. Ito H, Kawahara T, Terao H, et al. Predictive value of attenuation coefficients measured as Hounsfield units on noncontrast computed tomography during flexible ureteroscopy with holmium laser lithotripsy: a singlecenter experience. J Endourol 2012;26:1125-30.

22. Simsek A, Ozgor F, Akbulut MF, et al. Management of bladder stones associated with foreign bodies following incontinence and contraception surgery. Arch Ital Urol Androl 2014;86:108-11.

23. Halland SK, House JK, George LW. Urethroscopy and laser lithotripsy for the diagnosis and treatment of obstructive urolithiasis in goats and pot-bellied pigs. J Am Vet Med Assoc 2002;220:1831-4.

24. Ito H, Kawahara T, Terao H, et al. The most reliable preoperative assessment of renal stone burden as a predictor of stone-free status after flexible ureteroscopy with holmium laser lithotripsy: a single-center experience. Urology 2012;80:524-8.

25. Sofer M, Kaver I, Greenstein A, et al. Refinements in treatment of large bladder calculi: simultaneous 
percutaneous suprapubic and transurethral cystolithotripsy. Urology 2004;64:651-4.

26. Jeon SW, Park YK, Chang SG. Dystrophic calcification

Cite this article as: Lv J, Wang N, Zhu Y, Luo Q, Li Y, Li J. A meta-analysis and systematic review of holmium laser treatment of bladder stones. Transl Androl Urol 2021;10(8):3465-3475. doi: $10.21037 /$ tau-21-563 and stone formation on the entire bladder neck after potassium-titanyl phosphate laser vaporization for the prostate: a case report. J Korean Med Sci 2009;24:741-3. 